\title{
Enraizamento de estacas lenhosas de ameixeiras tratadas com ácido indolbutírico
}

\author{
Rooting of hardwood cuttings from plum treated with indolbutiric acid
}

\author{
Ubirajara Ribeiro Mindêllo Neto ${ }^{1}$ Charles Allan Telles ${ }^{2}$ \\ Luiz Antonio Biasi ${ }^{3}$
}

\section{RESUMO}

Considerando o grande interesse pela ameixeira no mercado de frutas, existe a necessidade de buscar técnicas mais eficientes na produção de mudas de qualidade e com maior uniformidade. Buscou-se, neste trabalho, verificar o potencial de enraizamento de estacas lenhosas de 12 cultivares de ameixeira (América, Amarelinha, Letícia, Pluma 7. Reubennel, Rosa Mineira, Santa Rita, Santa Rosa, Simka, The First, Wade e XV de novembro) tratadas com ácido indolbutírico (AIB), em concentrações de 0, 1000 e 3000mg L $L^{-1}$, em imersão rápida por 5 segundos na sua parte basal. O estudo foi desenvolvido de junho a setembro de 2004, na EMBRAPA Transferência de Tecnologia, localizada no município de Canoinhas, SC. Estacas lenhosas foram coletadas de plantas matrizes de dois anos, situadas em casa-de-vegetação e padronizadas com um comprimento médio de $12 \mathrm{~cm} e$ diâmetro de $6 \mathrm{~mm}$, sendo acondicionadas em bandejas de poliestireno expandido com 72 células de $0,000015 \mathrm{~m}^{3}$, contendo vermiculita como substrato e mantidas em casa de vegetação sem nebulização intermitente por 97 dias. $O$ delineamento experimental foi o inteiramente casualizado com quatro repetições e 12 estacas por parcela. As maiores porcentagens de enraizamento (acima de 70\%) foram obtidas nas estacas das cultivares $X V$ de Novembro, Rosa Mineira e Santa Rita. A aplicação de $1000 \mathrm{mg} \mathrm{L}^{-1} \mathrm{AIB}$, foi melhor no enraizamento de estacas de ameixeira proporcionando maior número de raízes por estaca e maior comprimento das raízes.

Palavras-chave: propagação vegetativa, Prunus salicina Lindl., estaquia, auxina exógena.

\section{ABSTRACT}

Considering the great interest for the plum tree in the fruit market, there is the necessity of searching for more efficient techniques in the plum plant propagation with quality and high uniformity. So this work aimed at verifying rooting potential of hardwood cuttings of 12 to cultivars of the plum tree (América, Amarelinha, Letícia, Pluma 7, Reubennel, Rosa Mineira, Santa Rita, Santa Rosa, Simka, The First, Wade and $X V$ de November) treated with indolbutiric acid (IBA), in concentrations of 0,1000 and $3000 \mathrm{mg} \mathrm{L}^{-1}$, in fast immersion per 5 seconds in its basal part. The study was developed from June to September, 2004, in the EMBRAPA Technology transfer, located in the city of Canoinhas, SC. Hardwood cuttings had been collected first plants of 2 years situated in green-house and standardized with an average length of $12 \mathrm{~cm}$ and diameter six $\mathrm{mm}$, being conditioned in polystyrene trays expanded with 72 cells of $0,000015 \mathrm{~m}^{3}$, contend vermiculita as substratum and kept in house of vegetation without intermittent mist per 97 days. The experimental delineation was entirely randomized with four replicates and 12 cuttings per parcel. The biggest rooting percentages (above of $70 \%$ ) had been gotten in the cuttings of them to cultivate $X V$ de November, Rosa Mineira and Santa Rita. The application of IBA $1000 \mathrm{mg} \mathrm{L}^{-1}$, was the best in the rooting of cuttings of plum, given biggest number of roots and length of the roots.

Key words: vegetative propagation, Prunus salicina Lindl., cutting, auxin.

\section{INTRODUÇÃO}

No Brasil, a ameixeira (Prunus salicina, Lindl.), é plantada principalmente nos Estados de Santa Catarina, Rio Grande do Sul, Paraná e São Paulo, devido a condições edafoclimáticas favoráveis para o cultivo (PASINATO et al., 1998).

${ }^{1}$ Embrapa Transferência de Tecnologia/SNT Canoinhas, Rod. BR 280, km 219, Caixa Postal 317, 89460-000, Canoinhas, SC, Brasil. Fone: (47) 624-0127. E-mail: ubirajara.encan@embrapa.br. Autor para correspondência.

${ }^{2}$ Programa de Pós-graduação em Agronomia, Produção Vegetal. Universidade Federal do Paraná (UFPR), Curitiba, Paraná, Brasil. E-mail: charles.allan@bol.com.br.

${ }^{3}$ Departamento de Fitotecnia e Fitossanitarismo, Setor de Ciências Agrárias, UFPR, Caixa Postal 19.061, 81531-990, Curitiba, PR, Brasil. Fone: (41) 350-5601. E-mail: biasi@ufpr.br. 
A propagação da ameixeira é comumente realizada pela enxertia, utilizando-se do pessegueiro (Prunus pérsica (L.) Batsch) como porta-enxerto, o qual é multiplicado por sementes. Assim, existe o risco de ocorrer segregação genética deste material, produzindo pomares desuniformes quanto ao porte e longevidade. Além disso, de acordo com KERSTEN (1990), a vida útil da planta fica limitada devido ao fato de o pessegueiro possuir menor longevidade do que a ameixeira.

A estaquia vem sendo empregada com sucesso na propagação de espécies frutíferas e é uma técnica de maior viabilidade econômica (ANTUNES et al., 2000), porém, para a ameixeira, não têm sido obtidos resultados satisfatórios no Brasil, seja pelo baixo potencial de enraizamento apresentado pelas cultivares, seja pela deficiência nas técnicas de enraizamento. A principal dificuldade para utilização da estaquia na propagação da ameixeira é a grande variabilidade de resposta encontrada entre as diversas cultivares existentes. Assim sendo, cada cultivar apresenta um comportamento diferenciado com relação aos fatores que afetam o enraizamento, principalmente com relação à época de estaqueamento, tipo de substrato, ambiente e reguladores de crescimento (SEGANFREDO et al., 1995).

No entanto, a propagação por estacas é uma prática que está sendo pesquisada em diversos países, onde se cultiva esta espécie, para a produção de portaenxertos ou mudas, dispensando a prática de enxertia (TOFANELLI et al., 2002)

Com o objetivo de incrementar o enraizamento de estacas de ameixeira, a aplicação de fitorreguladores sintéticos vem sendo amplamente utilizada, entre os quais se destaca o AIB (ácido indolbutírico), que foi utilizado por vários autores (RATHORE, 1983; LEMUS, 1987; SHARMA \& AIER, 1989; KERSTEN et al., 1993 e 1994; PASINATO et al.,1998). Porém, os resultados obtidos são bastante divergentes, não só com relação à concentração de AIB, mas também quanto sua interação com o tipo de estaca, época de realização da estaquia e cultivares.

O objetivo foi verificar o potencial de enraizamento de estacas lenhosas de cultivares de ameixeira tratadas com diferentes concentrações de AIB.

\section{MATERIAL E MÉTODOS}

O presente estudo foi desenvolvido no período de junho a setembro de 2004, na EMBRAPA Transferência de Tecnologia, localizada no município de Canoinhas, SC.
Foram utilizadas estacas lenhosas de 12 cultivares de ameixeira (América, Amarelinha, Letícia, Pluma 7, Reubennel, Rosa Mineira, Santa Rita, Santa Rosa, Simka, The First, Wade e XV de Novembro), coletadas em junho de 2004 de plantas matrizes com dois anos de idade, situadas em casa-de-vegetação com telado anti-afídeo da Embrapa. Após a coleta, as estacas foram levadas para laboratório e foram padronizadas com um comprimento médio de $12 \mathrm{~cm} \mathrm{e}$ diâmetro médio de $6 \mathrm{~mm}$.

As estacas foram tratadas com AIB, em concentrações de 0,1000 e $3000 \mathrm{mg} \mathrm{L}^{-1}$, em imersão rápida por 5 segundos na sua parte basal. $\mathrm{Na}$ concentração de $0 \mathrm{mg} \mathrm{L}^{-1}$ foi utilizada água destilada como testemunha. As concentrações de 1000 e 3000mg L ${ }^{-1}$ de AIB foram diluídas em álcool etílico 50\%. Após tratadas, as estacas foram acondicionadas em bandejas de poliestireno expandido com 72 células de $0,000015 \mathrm{~m}^{3}$, contendo vermiculita de grânulos médios, como substrato, e transferidas para casa-de-vegetação sem nebulização intermitente, com temperatura média de $23^{\circ} \mathrm{C}$ e $76 \%$ de umidade relativa do ar. A irrigação foi realizada manualmente a cada 30 minutos durante a manhã e a tarde.

O delineamento experimental foi o inteiramente casualizado com quatro repetições e 12 estacas por parcela, em arranjo fatorial 12 x 3 (cultivares $\mathrm{x}$ concentrações de AIB).

Após 97 dias de instalação do ensaio, foram analisadas a porcentagem de estacas enraizadas, sendo consideradas as estacas que apresentaram pelo menos uma raiz adventícia emitida, o número médio de raízes por estaca enraizada e o comprimento médio da maior raiz por estaca enraizada. Os resultados foram analisados, comparando-se os níveis dos fatores cultivar e concentrações de AIB através do teste de Scott-Knott a 5\% de significância.

\section{RESULTADOS E DISCUSSÃO}

Com relação à porcentagem de enraizamento, não houve interação significativa entre cultivares e concentração de AIB. A porcentagem de enraizamento das estacas variou conforme a cultivar (Tabela 1) onde as cultivares XV de Novembro, Rosa Mineira e Santa Rita foram superiores às demais, alcançando porcentagens de enraizamento acima de $70 \%$, o que são porcentagens razoáveis, pelo fato de ameixeira apresentar dificuldades de enraizamento de estacas, principalmente no caso das estacas lenhosas que dispensariam estruturas especiais de enraizamento.

As piores taxas de enraizamento foram obtidas com as cultivares Simka, Reubennel e Wade 
Tabela 1 - Porcentagem de enraizamento nas estacas de cultivares de ameixeira, tratadas com ácido indolbutírico (AIB). Média das três concentrações e comparação nas concentrações individuais de AIB. Canoinhas, SC, 2004.

\begin{tabular}{lc}
\hline Cultivares & Enraizamento(\%) \\
\hline Santa Rita & $70,83 \mathrm{a}$ \\
XV de Novembro & $81,25 \mathrm{a}$ \\
Amarelinha & $27,77 \mathrm{~b}$ \\
América & $41,66 \mathrm{~b}$ \\
Santa Rosa & $28,47 \mathrm{~b}$ \\
Letícia & $31,25 \mathrm{~b}$ \\
Wade & $18,75 \mathrm{c}$ \\
Pluma 7 & $41,66 \mathrm{~b}$ \\
Simka & $2,77 \mathrm{c}$ \\
The First & $34,02 \mathrm{~b}$ \\
Reubennel & $18,75 \mathrm{c}$ \\
Rosa Mineira & $72,22 \mathrm{a}$ \\
\hline AIB (mg L ${ }^{-1}$ ) & $23,78 \mathrm{~b}$ \\
\hline 0 & $53,12 \mathrm{a}$ \\
1000 & $40,25 \mathrm{a}$ \\
\hline & \\
\hline & \\
\hline
\end{tabular}

Médias seguidas de mesma letra não diferem pelo teste de ScottKnott a 5\% de probabilidade de erro.

(abaixo de 20\%), sendo inferiores as cultivares Amarelinha, América, Santa Rosa, Letícia, Pluma 7 e The First, que apresentaram uma porcentagem de enraizamento entre 27 a 40\%. Resultados semelhantes foram obtidos por TOFANELLI et al. (2002), DUTRA et al. (1998), SEGANFREDO et al. (1995), que analisaram diferentes cultivares de ameixeira e indicaram que cada cultivar apresenta uma capacidade intrínseca de emissão de raízes. O potencial natural para enraizar da cultivar Frontier (acima de 50\%) foi demonstrado por SEGANFREDO et al. (1995), que também verificaram porcentuais de enraizamento inferiores a $5 \%$, para as cultivares Beauty, All Producer e Roxa de Itaquera, não demonstrando efeito significativo da aplicação de AIB.

Estes resultados também confirmam os obtidos por RATHORE (1983), SHARMA \& AIER (1989) e KERSTEN et al. (1993), que encontraram variação na porcentagem de estacas enraizadas nas diferentes concentrações de fitoregulador.

Com relação às concentrações (1000 e 3000mg $\mathrm{L}^{-1}$ ) de AIB, as duas não diferiram entre si, obtendo 53,12 e 40,25\% de enraizamento, respectivamente, porém, foram melhores do que a testemunha (23,78\%) (Tabela 1). Efeitos semelhantes foram obtidos por TOFANELLI et al. (2002), que analisando estacas semilenhosas das cultivares Carmesin, Gema de ouro, Januária e Reubennel, obtiveram o maior enraizamento (55,95\%) na concentração de $3000 \mathrm{mg} \mathrm{L}^{-1}$ de AIB. Outros resultados foram obtidos por KERSTEN et al. (1994), quando compararam a concentração de AIB e a porcentagem de enraizamento da cultivar Reubennel, onde o porcentual de enraizamento teve maior incremento de zero (0,8\%) até $2000 \mathrm{mg} \mathrm{L}^{-1}$ (39,8\%), sendo que a partir desta concentração, praticamente, ocorreu uma estabilização do enraizamento. Este comportamento pode ser resultado do balanço hormonal favorável ao enraizamento ocasionado pela maior concentração do fitorregulador.

Para as variáveis número de raízes e comprimento da maior raiz houve interação entre os fatores (Tabela 2). Verificou-se também, que houve grande diferença entre as cultivares e entre as concentrações de AIB aplicadas. Para a testemunha (sem aplicação de AIB), as cultivares Santa Rita e XV de Novembro apresentaram maior número de raízes, 4,53 e 6,79, respectivamente. Na concentração de 1000mg L ${ }^{-1}$ de AIB, a cultivar XV de Novembro foi superior às demais, com uma média de 15,56 raízes por estaca. Em seguida, vieram as cultivares Santa Rita $(10,12)$, Rosa Mineira (7,41), América (5,35), Pluma 7 $(4,16)$, Letícia $(3,83)$, The First $(3,79)$, Santa Rosa $(3,02)$, Amarelinha (1,87), Wade $(1,79)$, Reubennel $(1,21)$ e Simka $(0,14)$, porém na concentração de $3000 \mathrm{mg} \mathrm{L}^{-1} \mathrm{de}$ AIB, as estacas emitiram menos raízes, provavelmente por um desbalanço hormonal da estaca, e um possível efeito fitotóxico.

Os números de raízes de algumas cultivares foram bastante satisfatórias, quando comparados a outros resultados com estaquia de ameixeira, como os obtidos por TOFANELLI et al. (2002), que registraram para estacas semilenhosas das cultivares Carmesin, Gema de Ouro e Januária um número de 2,98; 3,08 e 5,47, respectivamente com 3000 $\mathrm{mg} \mathrm{L}^{-1} \mathrm{de}$ AIB. RUFATO \& KERSTEN (2000) também observaram que o AIB aumentou o número de raízes em estacas lenhosas de pessegueiro das cultivares Esmeralda e BR2.

Nos resultados apresentados na tabela 2, pode-se observar que existe grande variação do comprimento médio da maior raiz, entre as cultivares e entre as concentrações aplicadas. Os melhores resultados foram verificados para as cultivares Santa 
Tabela 2 - Número médio de raízes e comprimento médio da maior raiz em centímetros nas estacas de cultivares de ameixeira em função de diferentes concentrações de AIB. Canoinhas, SC, 2004.

\begin{tabular}{|c|c|c|c|c|c|c|}
\hline \multirow{3}{*}{ Cultivares } & \multicolumn{3}{|c|}{ Número médio de raízes } & \multicolumn{3}{|c|}{ Comprimento da maior raiz (cm) } \\
\hline & 0 & 1000 & 3000 & 0 & 1000 & 3000 \\
\hline & \multicolumn{6}{|c|}{ AIB (mg L $\left.{ }^{-1}\right)$} \\
\hline Santa Rita & 4,53 a $C$ & 10,12 b A & 7,00 a $\mathrm{B}$ & 1,93 a $\mathrm{C}$ & $3,40 \mathrm{~b} \mathrm{~A}$ & $2,34 \mathrm{~b} B$ \\
\hline XV de Novembro & 6,79 a $\mathrm{C}$ & 15,56 a $\mathrm{A}$ & 6,89 a B & 1,65 a $\mathrm{C}$ & 5,37 a $\mathrm{A}$ & 2,99 b B \\
\hline Amarelinha & $0,73 \mathrm{~b} \mathrm{C}$ & $1,87 \mathrm{~g} \mathrm{~A}$ & $1,06 \mathrm{~d} B$ & $0,69 \mathrm{~b} \mathrm{C}$ & 1,61 с A & 1,44 с B \\
\hline América & 0,95 b C & $5,35 \mathrm{~d} A$ & $1,06 \mathrm{~d} B$ & 0,52 b C & 3,12 b A & $1,00 \mathrm{~d} B$ \\
\hline Santa Rosa & 0,79 b C & $3,02 \mathrm{f} \mathrm{A}$ & $1,52 \mathrm{~d} B$ & $0,47 \mathrm{~b} \mathrm{C}$ & 1,64 с A & $0,77 \mathrm{~d} B$ \\
\hline Letícia & 0,25 b C & 3,83 e $A$ & $1,23 \mathrm{~d} B$ & 0,19 b C & 2,15 с A & $1,14 \mathrm{~d} \mathrm{~B}$ \\
\hline Wade & $0,02 \mathrm{~b} \mathrm{C}$ & $1,79 \mathrm{~g} \mathrm{~A}$ & $0,94 \mathrm{~d} B$ & 0,02 b C & 1,52 с A & $0,86 \mathrm{~d} B$ \\
\hline Pluma 7 & 0,35 b C & 4,16 е $\mathrm{A}$ & 2,16 с В & 0,31 b C & 3,26 b A & 2,31 b B \\
\hline Simka & $0,00 \mathrm{~b} \mathrm{C}$ & 0,14 h A & 0,08 e $\mathrm{B}$ & $0,00 \mathrm{~b} \mathrm{C}$ & $0,14 \mathrm{~d} A$ & 0,08 е $B$ \\
\hline The First & 0,29 b C & 3,79 е $A$ & 1,37 d B & 0,49 b C & 1,35 с A & $0,71 \mathrm{~d} B$ \\
\hline Reubennel & 0,02 b C & $1,21 \mathrm{~h} \mathrm{~A}$ & $1,00 \mathrm{~d} B$ & 0,04 b C & 1,06 с A & $0,83 \mathrm{~d} B$ \\
\hline Rosa Mineira & 1,52 b C & 7,41 с A & 5,70 b B & 1,59 а C & 5,10 a $A$ & 3,95 а B \\
\hline
\end{tabular}

Médias seguidas de mesma letra minúscula na coluna, e maiúscula na linha, não diferem, pelo teste de Scott-Knott a 5\% de probabilidade de erro.

Rita, XV de Novembro e Rosa Mineira, nas concentrações de 0 e $1000 \mathrm{mg} \mathrm{L}^{-1}$, e com 3000mg L-1 somente a Rosa Mineira foi superior.

Importantes correlações puderam ser observadas entre os parâmetros estudados neste experimento, pois se verificou que, quanto maior o enraizamento, maior o número e comprimento da maior raiz, confirmado por resultados obtidos por RATHORE (1983), SHARMA \& AIER (1989), KERSTEN et al. (1993 e 1994), PASINATO et al. (1998), TOFANELLI et al. (2002), segundo os quais a melhor concentração de AIB é condicionada ao tipo de material, de cultivar e de variável analisada.

\section{CONCLUSÕES}

A propagação das ameixeiras 'Santa Rita', 'XV de Novembro’ e ‘Rosa Mineira’, utilizando estacas lenhosas, constitui uma alternativa viável para obtenção de mudas. O uso de AIB aumentou o enraizamento das cultivares de ameixeira, na concentração de $1000 \mathrm{mg} \mathrm{L}^{-1}$. As cultivares Reubennel, Simka e Wade, apresentam baixo potencial de emissão de raízes.

\section{REFERÊNCIAS}

ANTUNES, L.E.C. et al. Propagação de cultivares de amoreirapreta (Rubus spp) através de estacas lenhosas. Revista Brasileira de Fruticultura, Jaboticabal, v.22, n.2, p.195199, 2000.

DUTRA, L.F. et al. Efeito da aplicação prévia de ethephon em ameixeira (Prunus salicina Lindl) e do IBA no enraizamento de suas estacas. Scientia Agrícola, Piracicaba, v.55 n.2, p.296304, 1998.

KERSTEN, E. Efeito do boro, zinco e ácido indolbutírico no enraizamento de estacas de dois cultivares de ameixeira (Prunus salicina, Lindl.). 1990. 109f. Tese (Doutorado em solos e nutrição de plantas) - Escola Superior de Agricultura Luiz de Queiroz, Universidade de São Paulo, Piracicaba.

KERSTEN, E. et al. Efeito do ácido indolbutírico no enraizamento de estacas de ramos de plantas de ameixeira (Prunus salicina, Lindl). Scientia Agrícola, Piracicaba, v.50, n.1, p.19-26, 1993.

KERSTEN, E. et al. Influência do ácido indolbutírico no enraizamento de estacas de ameixeira (Prunus salicina, Lindl.). Revista Brasileira de Fruticultura, Cruz das Almas, v.16, n.1, p.215-222, 1994.

LEMUS, S.G. Propagacion per estaca leñosa de portainjertos clonales de ciruelo. Agricultura Técnica, Santiago, v.47, n.1, p.75-77, 1987.

Ciência Rural, v.36, n.2, mar-abr, 2006. 
PASINATO, V. et al. Enraizamento de estacas lenhosas de cultivares de ameixeira (Prunus spp.), em condições de campo. Scientia Agrícola, Piracicaba, v.55, n.2, p.265-268, 1998.

RATHORE, D.S. Note on the effect of indolebutyric acid n rooting of plum cuttings under mist. Indian Journal of Horticulture, Bangalore, v.40, n.3/4, p.205-206, 1983.

RUFATO, L.; KERSTEN, E. Enraizamento de estacas de pessegueiro (Prunus persica (L.) Batsch), cvs Esmeralda e BR2, submetidas à estratificação e ao ácido indolbutírico. Revista Brasileira de Fruticultura, Jabotical, v.22, n.2, p.191-194, 2000.
SEGANFREDO, R. et al. Influência do ácido indolbutírico e de épocas de coleta de estacas no enraizamento de cultivares de ameixeira (Prunus salicina, Lindl.). Revista Brasileira de Agrociência, Pelotas, v.1, n.1, p.40-42, 1995.

SHARMA, S.D.; AIER, N.B. Seasonal rooting behaviour of cuttings of plum cultivar as influenced by IBA treatments. Scientia Horticulturae, Amsterdan, v.40, p.297-303, 1989.

TOFANELLI, M.B.D. et al. Enraizamento de estacas lenhosas e semilenhosas de cultivares de ameixeira com várias concentrações de ácido indolbutírico. Revista Brasileira de Fruticultura, Jaboticabal, v.24, n.2, p.509-513, 2002 